\title{
TRABAJANDO POR UN FUTURO MÁS PROMETEDOR
}

La Comisión Mundial de la OIT sobre el Futuro del Trabajo lanzó el 22 de enero del 2019 su informe sobre el futuro del trabajo en el que insta a los gobiernos a comprometerse a adoptar una serie de medidas a fin de hacer frente a los desafíos generados por los profundos cambios sin precedentes que tienen lugar en el mundo del trabajo. Este informe es el resultado de un examen realizado a lo largo de 15 meses por los 27 miembros de la Comisión Mundial, constituida por destacadas personalidades del mundo empresarial, laboral y académico, grupos de reflexión y organizaciones gubernamentales y no gubernamentales.

En él, la Comisión propone una visión de un programa centrado en las personas, basado en la inversión en las capacidades de los individuos, las instituciones laborales y en el trabajo decente y sostenible. Entre las diez recomendaciones se encuentran:

- Una garantía universal de empleo que proteja los derechos fundamentales de los trabajadores garantice un salario que permita un nivel de vida digno, horas de trabajo limitadas y lugares de trabajo seguros y saludables.

- Una protección social garantizada desde el nacimiento hasta la vejez que atienda las necesidades de las personas a lo largo de su ciclo de vida.

- Un derecho universal al aprendizaje permanente que permita que las personas se formen, adquieran nuevas competencias y mejoren sus cualificaciones.

- Una gestión del cambio tecnológico que favorezca el trabajo decente, incluso a través de un sistema de gobernanza internacional de las plataformas digitales de trabajo.

- Mayores inversiones en las economías rurales, verdes y del cuidado.

- Una agenda transformadora y mensurable a favor de la igualdad de género.

- La reestructuración de los incentivos a las empresas a fin de estimular las inversiones a largo plazo.

El informe destaca que "nos esperan innumerables oportunidades para mejorar la calidad de vida de los trabajadores, ampliar las opciones disponibles, cerrar la brecha de género, revertir los estragos causados por las desigualdades a nivel mundial y mucho más. Sin embargo, nada de ello ocurrirá por sí mismo. Sin esas medidas enérgicas, nos dirigiremos a un mundo en el que se ahondarán las desigualdades e incertidumbres existentes" haciendo un llamado a favor de una respuesta colectiva a escala mundial ante los trastornos que estos ocasionan en el mundo del trabajo. 


\section{IUSLabor 1/2019}

El informe además pone de manifiesto el "papel único" que la OIT debe desempeñar en la elaboración y puesta en práctica del "programa centrado en las personas" en el sistema internacional y exhorta a la Organización a dar prioridad a la implementación de las recomendaciones del informe.

A continuación, reproducimos el resumen del informe para información general:

https://www.ilo.org/global/topics/future-of-work/publications/WCMS_662541/lang-es/index.htm

IUSLabor 1/2019, ISSN 1699-2938, p. 353-354

DOI 10.31009/IUSLabor.2019.101.13 